\title{
DESDOBRAMENTOS DO PROCESSO DE PATRIMONIALIZAÇÃO DA PAISAGEM CARIOCA NA ALIMENTAÇÃO: O CASO DOS FOOD TRUCKS
}

Unfolding of the Carioca Landscape Heritage Process in food: the case of food trucks

Despliegue del Proceso del Patrimonio Paisajístico Carioca en la alimentación: el caso de los food trucks

Maria Amália Silva Alves de Oliveira

Universidade Federal do Estado do Rio de Janeiro

(UNIRIO), Brasil

m_amali@hotmail.com

Gabriela Elis da Cunha

Universidade Federal do Estado do Rio de Janeiro

(UNIRIO), Brasil

gabrielaelisdacunha@yahoo.com.br
DOI: https://doi.org/10.18472/cvt.20n2.2020.1859

Redalyc: http://www.redalyc.org/articulo.oa? id $=115464354011$

Recepción: 13 Agosto 2020

Aprobación: 31 Agosto 2020

\section{Resumo:}

A partir do processo de reconhecimento do bem "Rio de Janeiro: Paisagens Cariocas entre a Montanha e o Mar" enquanto patrimônio inserido na categoria Paisagem Cultural pela UNESCO, o presente trabalho objetiva descrever a inserção dos food trucks no contexto das práticas alimentares acionadas durante o período em que a cidade do Rio de Janeiro concentrou a recepção de vários eventos mundiais e assim, discutir sentidos e significados culturais atribuídos ao alimento e ao ato de alimentar-se em contexto de articulação entre patrimônio e turismo.

PalaVras-chave: Food trucks, Patrimônio, Turismo.

\section{Abstract:}

Based on the recognition process of the property "Rio de Janeiro: Rio Landscapes between the Mountain and the Sea" as a heritage inserted in the Cultural Landscape category by UNESCO, the present work aims to describe the insertion of food trucks in the context of the food practices triggered during the a period in which the city of Rio de Janeiro concentrated the reception of various world events and, thus, to discuss cultural meanings and meanings attributed to food and the act of eating in a context of articulation between heritage and tourism.

KEYWORDS: Food trucks, Heritage, Turism.

\section{RESUMEN:}

A partir del proceso de reconocimiento de la propiedad "Río de Janeiro: Paisajes de Río entre la Montaña y el Mar" como patrimonio insertado en la categoría Paisaje Cultural por la UNESCO, el presente trabajo tiene como objetivo describir la inserción de los food trucks en el contexto de las prácticas alimentarias desencadenadas durante el un período en el que la ciudad de Río de Janeiro concentró la recepción de diversos eventos mundiales y, así, discutir significados culturales y significados atribuidos a la comida y al acto de comer en un contexto de articulación entre patrimonio y turismo.

Palabras ClaVe: Food trucks, Patrimonio, Turismo.

\section{INTRODUÇÃo}

Os anos que antecederam os dois megaeventos esportivos sediados no Rio de Janeiro, a Copa do Mundo da FIFA de 2014 e as Olimpíadas de 2016, foram marcados por uma série de decretos municipais que transformaram manifestações e símbolos culturais, que particularizam a forma de viver do carioca, em patrimônio de natureza imaterial. Esse processo tem como marco divisor a candidatura do Rio ao título 
de Patrimônio Mundial da Humanidade na categoria Paisagem Cultural através do dossiê "Rio de Janeiro: Paisagens Cariocas entre a Montanha e o Mar" e cuja aprovação ocorreu em Sessão do Comitê do Patrimônio Mundial, realizada em São Petersburgo, na Rússia, no dia $1^{\circ}$ de Julho de 2012. Por ocasião da elaboração do dossiê, o então presidente do Instituto do Patrimônio Histórico e Artístico Nacional (IPHAN) defendeu que “(...) a valorização do patrimônio cultural se intensificará a partir da compreensão de seus significados históricos e de seus benefícios sociais e econômicos" (Almeida, 2007), revelando assim que a concepção de patrimônio está agregada tanto aos usos e atividades dos espaços patrimoniais, quanto ao que pode representar oportunidades econômicas.

Nesta linha de raciocínio, a proposta candidatada buscou apresentar as propriedades paisagísticas dos locais e suas articulações com a vida cultural e natural, onde se encontram monumentos, fazeres, ecossistemas, e assim o Rio de Janeiro tornou-se a "primeira cidade" a ser nomeada Patrimônio Mundial na referida categoria. Em decorrência deste reconhecimento, a Prefeitura da Cidade do Rio de Janeiro, através do Decreto No 35.879 de 05 de Julho de 2012, dispõe sobre o Rio Como Patrimônio da Humanidade, criando o Instituto Rio Patrimônio da Humanidade (IRPH) que passa a deter, como uma de suas principais atribuições, a gerência do sítio reconhecido pela Organização das Nações Unidas para a Educação, a Ciência e a Cultura (UNESCO) como Patrimônio Mundial da Humanidade.

No bojo deste processo, o samba, a bossa nova, o futebol, o carnaval de rua e as tradicionais festividades religiosas foram inscritas na lista de patrimônio de natureza imaterial da cidade do Rio de Janeiro e outras iniciativas, como a construção do marco referencial da gastronomia, levada a efeito em âmbito estadual, revelam um verdadeiro "boom" de bens patrimonializados em um momento no qual a cidade se preparava para receber os megaeventos anteriormente citados.

Neste contexto, a proposta é analisar o caso dos food trucks, inserindo-os na articulação da relação entre patrimônio e turismo, buscando destacar os sentidos e valores atribuídos ao alimento e ao ato de alimentarse em tal conjuntura. Desta forma, o trabalho busca preencher uma lacuna no que tange a pouca produção sobre essa plataforma de fornecimento de comercialização de alimentos pelo viés de análise cultural.

\section{Breve contextualizaçÃo teórica da relaÇão política entre turismo E PATRIMÔNIO}

Segundo Abreu (2015), a emergência da noção de preservação e salvaguarda do patrimônio é um fenômeno próprio do Ocidente moderno, que vem ocupando cada vez mais os debates internacionais. Autores como Choay (2006), Poulot (2011) e Chuva (2017) apontam o século XVIII como o momento em que a noção de patrimônio desponta para o mundo ocidental. Emergindo no contexto da Revolução Francesa (1789-1799), período de intensas transformações sociais, a ideia de patrimônio se estabelece na França objetivando a criação de um passado comum, que representasse os novos ideais emanados pelos valores propostos pela Revolução. A partir de então, foi se estabelecendo no pensamento coletivo a noção de bens públicos, ou seja, que pertenceriam a todo o povo e não somente a indivíduos ou grupo dominante. No século seguinte, essa ideia irá se expandir por todo o mundo ocidental, sendo interpretada por cada nação de acordo com suas particularidades.

No caso brasileiro é possível identificar no período imperial uma busca pelo fortalecimento de uma identidade nacional através da instituição de patrimônio histórico nacional. A criação do Arquivo Nacional e do Instituto Histórico e Geográfico Brasileiro (IHGB), são exemplos de instituições cujos objetivos residiam na seleção de uma determinada memória do país, sendo essa vinculada aos valores do Império. Segundo Fernandes (2010), dentre as duas Instituições, o IHGB tem papel de destaque, pois foi "um dos órgãos precursores da política de preservação do patrimônio histórico nacional” (p. 04). A despeito deste esforço, é a criação do Serviço do Patrimônio Histórico e Artístico Nacional (SPHAN), através do Decreto-Lei n ${ }^{\circ}$ 25/1937, que de fato surge uma política nacional voltada para o patrimônio nacional. Entretanto, assim 
como as instituições criadas no período imperial, o SPHAN, posteriormente IPHAN (Instituto Histórico e Artístico Nacional), também obedecia a um projeto de governo, sendo esse da Era Republicana.

Há uma preocupação com medidas concretas de proteção aos bens patrimonializados, sendo uma delas a implementação do Programa de Cidades Históricas, que teve a participação do consultor da UNESCO, Michel Parent. Esta fase, localizada em termos cronológicos na década de 1960, revela uma mudança na concepção de patrimônio, que passa a abranger os elementos naturais e, ao mesmo tempo, marca a inserção do turismo no debate internacional sobre patrimônio, pois tal atividade passa a ser interpretada como instrumento de preservação do mesmo e propulsora de economia e renda para os países.

Rios e Oliveira (2018) destacam que a inserção da atividade turística nos debates ocorridos no âmbito da UNESCO remonta a construção da categoria "política cultural”, que acompanha toda a trajetória histórica da organização. Neste processo, a entidade teria contribuído na propagação de uma noção de política cultural que orienta os contornos da forma de fazer e pensar ações públicas relacionadas à cultura em diferentes lugares. No que tange a política cultural em sua relação com o patrimônio, as autoras esclarecem que esta reside na experiência que resultou no denominado Programa de Assistência Técnica da UNESCO iniciado com a "Campanha da Núbia", ação caracterizada por um conjunto de medidas técnicas orientadas por especialistas ligados a organização em prol da salvaguarda de bens que estavam em perigo de perda em decorrência da construção da represa de Assuã, localizada no sul do Egito, que inundaria toda a região onde encontravam-se bens de grande representatividade histórica e cultural para a humanidade.

A Campanha da Núbia promoveu uma revisão no pensamento acerca do patrimônio no âmbito da UNESCO, pois foi através dessa experiência que a organização percebeu o interesse do público em relação a proteção de bens em risco de perda, tendo em vista que fluxos de visitantes passaram a se deslocar para o local. Essa percepção favoreceu a concepção que remonta à associação entre patrimônio e desenvolvimento econômico. Nesse contexto, a UNESCO passa a atrelar a preservação do patrimônio ao turismo, ocasionando a inserção deste em programas, projetos e planos pensados na perspectiva de retorno dos investimentos e dos custos que a manutenção técnica destes bens acarreta (Rios \& Oliveira, 2018).

A concepção de turismo enquanto instrumento de preservação do patrimônio cultural em seus desdobramentos no Brasil já foi apontada em trabalhos como os de Leal (2008), Correa (2015) e Aguiar (2016), e demonstram o estímulo ao denominado turismo cultural no intuito da preservação do patrimônio cultural, cujas premissas eram difundidas nas missões realizadas pelos técnicos contratados pela UNESCO nos processos de assistência técnica, semelhantes ao desenvolvido em Assuã. Concordando com as autoras, Rios e Oliveira (2018) demonstram que no Brasil a assistência técnica deu-se pela missão chefiada por Michel Parent, técnico do Serviço Principal de Inspeção dos Monumentos e de Inspeção de Sítios na França que aqui esteve nos anos de 1966 e 1967 e produziu um relatório de viagem e inspeção do patrimônio histórico nacional intitulado "Proteção e valorização do patrimônio cultural brasileiro no âmbito do desenvolvimento turístico e econômico”. A visão de Parent reproduziu os inúmeros debates ocorridos naquela década, refletindo a concepção que o turismo vinha recebendo como atividade de promoção, desenvolvimento e sustento do patrimônio cultural.

Pelo exposto, observa-se como a noção de política cultural difundida pela UNESCO recaiu sobre o tema patrimônio. Ainda nesse âmbito, ao debate sobre a proteção do patrimônio através do turismo, foram sendo agregados temas como memória, identidade cultural e desenvolvimento sustentável. Ao analisarmos em perspectiva histórica a introdução de tais temas na agenda de diretrizes que pautaram a elaboração e condução da política cultural dos países membros da ONU é possível perceber que, nas diversas conferências promovidas pela UNESCO, a atividade turística sempre foi destacada como vetor de promoção da preservação do patrimônio e, mais recentemente, vem sendo difundida a noção de que essa prática faculta o desenvolvimento e afirmação cultural. Ao longo deste processo, a atividade turística capaz de reunir as diretrizes apontadas para a política cultural que norteia a política voltada para a preservação do patrimônio cultural em seus desdobramentos citados, foi denominado Turismo Cultural pela UNESCO, sendo esse o 
segmento evocado pela organização em distintos programas e projetos que orientam as políticas dos países membros.

Ao discorrer sobre atuação e representação de grupos sociais específicos no campo do turismo, Jafari (2005) o faz a partir da perspectiva de "plataformas de abordagem" elencando cinco que, analisadas pelo viés dos envolvidos no fenômeno turístico, revelam uma contextualização histórica e cronológica acerca de concepções do pensamento do e/ou sobre o turismo. Na quinta plataforma, o autor chama a atenção para as estruturas de poder presentes na orientação do processo de indução da atividade turística. Denominada como plataforma de interesse público, esta visão do e/ou sobre o turismo surge no início do século XXI, quando a atividade turística passa a ser interpretada como um fenômeno sociopolítico poderoso por deter função pública relevante.

Jafari (2005) exemplifica a revisão do olhar sobre o turismo a partir do estabelecimento de uma agenda pública do turismo que pode ser observada em vários níveis e desdobramentos, como a conversão da Organização Mundial de Turismo (OMT) em uma agência da ONU em clara proposta de antecipação e desenvolvimento de uma agenda futura sendo o turismo inserido em diversas ações transversais. No bojo do estabelecimento de agendas públicas de turismo, o patrimônio torna-se relevante quando orienta processos de atribuição de valor a espaços, lugares e práticas culturais como forma de ativar a atividade turística, daí a relevância de análises como a aqui proposta.

\section{Metodologia}

Ao recuperar a trajetória da noção de patrimônio no intuito de conjugá-la com a atividade turística, buscou-se demonstrar que na atualidade a relação entre turismo e patrimônio alcançou um nível de complexidade pois o debate permeia instâncias de âmbitos nacionais e internacionais. Neste contexto, evidencia-se que análises e estudos que contemplem tal relação demandam recorrer a vários trabalhos e autores de disciplinas distintas do Turismo. Tribe (1997), ao discutir uma epistemologia do Turismo, apoiou-se na perspectiva filosófica e sociológica do conhecimento para sugerir um modelo para compreensão do Turismo. Em tal proposta, o autor revê o uso de conceitos, contornos, limites e a categorização dos estudos de Turismo e defende que este não é uma disciplina e sim, um campo. Sua defesa é estruturada na afirmativa de que a área do Turismo é composta por dois tipos de saberes: o saber que busca o que é uma coisa, denominado pelo autor como proposicional e o outro, considerado pelo autor como processual, que se preocupa em saber como uma coisa é feita.

Concordando com Tribe (1997) acerca da perspectiva de que a produção do conhecimento não se dá somente por via disciplinar e engessar o Turismo como disciplina empobreceria um fenômeno cujo estudo permite e requer distintas abordagens, recorre-se a Barreto (2003), que legitima a necessidade do concurso das Ciências Sociais nas pesquisas em Turismo e em seu planejamento a despeito da referida autora ter se debruçado sobre a contribuição teórica das Ciências Sociais como um todo, para o presente artigo, nos deteremos em uma das disciplinas que a compóem: a Antropologia.

Reconhecida por trazer uma concepção de cultura que compreende aspectos materiais e simbólicos da produção humana, a Antropologia busca captar os sentidos e significados no processo de interação social, valendo-se de um repertório metodológico cuja base assenta-se na pesquisa de campo. Técnica essa que exige a presença do pesquisador no local pesquisado, o que resulta na denominada observação participante e cujo objetivo é a produção de uma "descrição densa" a partir da interpretação de toda uma "teia de significados" inerentes a essas relações (Goldenberg, 2007, p. 23). Ainda que a noção de campo seja na Antropologia fortemente associada a presença do pesquisador junto a grupos culturais distintos do seu e muitas vezes geograficamente distantes, ao longo do tempo tal noção vem sendo ressignificada.

Autores como Giumbelli (2002) e Cunha (2004) chamam a atenção para a pesquisa em arquivos de distintas naturezas. Ambos os autores alargam a noção de pesquisa de campo demonstrando que em tais 
espaços a presença do antropólogo/pesquisador revela as mesmas tensões e sentidos atribuídos ao "estar lá” que impera na noção clássica de trabalho de campo. Em tal perspectiva, o que é denominado em outras áreas de produção de conhecimento como 'pesquisa documental', em termos antropológicos equivale ao tratamento dado a documentos e demais fontes textuais. Enquanto "vozes nativas" a serem interpretadas como materializações de visões de mundo e concepções carregadas de sentidos culturalmente construídos, manifestadas em pontos de vistas, notícias, cartas, filmes, gravações, fotografias, legislações, entre outras formas de expressões de pensamentos de pessoas, grupos e instituições sociais (Cunha, 2004, p. 293).

Os argumentos de Giumbelli (2002) e Cunha (2004), no que tange aos documentos serem tomados enquanto "vozes nativas", colaboram para a ampliação das possibilidades de análise antropológica, pois as etnografias são sempre pensadas enquanto resultado de uma experiência que envolve sobretudo o "estar lá", são agora também passíveis de construção a partir de outros espaços, aspecto que também se estende aos meios virtuais, pois as "vozes nativas" manifestam-se nos mais variados espaços e formas. Assim sendo, a pesquisa de campo é, no presente trabalho, articulada às distintas noções de "campo", aspecto que resultou em coleta de dados em fontes documentais, virtuais e/ou digitais, e de observação participante composta por frequência aos food trucks e realização de entrevistas. A coleta dos dados foi precedida por exaustiva pesquisa bibliográfica, sendo essa conceitualmente compreendida como uma modalidade de estudo e análise de documentos de domínio científico tais como livros, periódicos, enciclopédias, ensaios críticos, dicionários e artigos científicos (Oliveira, 2007, p. 69).

Apreciado em etapas de pesquisa, o repertório metodológico exposto e orientado pelo referencial da Antropologia facultou, no âmbito da pesquisa bibliográfica, a produção da reflexão contextualizada no item anterior em que a literatura referenciada conduziu o entendimento da relação entre processos de patrimonialização em sua relação com a atividade turística enquanto processo de turismização. De acordo com Mendonça (2010), o conceito de "turistificação" toma o espaço como elemento de intervenção e apropriação pelo turismo, enquanto o conceito de "turismização" designa fenômenos, ou percepções destes, a partir da perspectiva de um processo. Assim, turismização é um processo histórico de construção de um fenômeno associado a um processo de interiorização das diferentes facetas do turismo pelos grupos e pelas pessoas, que influencia nas relações e no modo de vida de determinado lugar (Mendonça, 2010). Neste artigo, turismização remete também à transformação do espaço, mas em um processo que considera o contexto global e universalizante, que é responsável não apenas pela alteração no estatuto e na utilização dos lugares, mas também pela influência nas relações, modos de vida e identidades.

Tendo a pesquisa bibliográfica conduzido o olhar conferido a análise do processo, objeto do presente artigo, a etapa de campo composta pela pesquisa em documentos, observação in loco e entrevistas demonstrou que o processo de patrimonialização da paisagem carioca promoveu desdobramentos nas formas de apropriação do espaço urbano pela gastronomia. Assim sendo, na próxima seção serão apresentados os resultados deste processo de turismização tomando como referência o caso dos food trucks.

\section{Resultados}

\subsection{Food trucks}

Mudanças significativas acerca da cozinha, da comida e dos ritos de partilha no momento da alimentação ocorreram a partir da década de 1970, ocasião em o ambiente doméstico deixou de ter a primazia como único ponto para nutrição. Neste mesmo período, nos centros urbanos que se consolidavam no Brasil, redes internacionais de lanchonetes se instalaram no país, como por exemplo o McDonald's, em que o conceito de alimentação envolvia aspectos até então incomuns na vida social brasileira, como a rapidez na entrega e no consumo do alimento. Criada pelos irmãos Richard e Maurice McDonald, é atribuído a eles a criação 
do termo fast food, ou seja, comida rápida (Freixa \& Dolores, 2017) e cuja aceitação do público consumidor acabou por fortalecer uma nova orientação no sistema cultural e na alimentação contemporânea, bem como no processo de produção em massa dos alimentos e para as massas.

Ainda considerando o crescimento dos centros urbanos, em paralelo às mudanças no estilo de vida nas cidades e na forma de se relacionar com o alimento e as refeições, a comida de rua se consolidou como alternativa legítima para refeições e passou a abranger diferentes grupos de indivíduos. Com profundos impactos nas estruturas das sociedades e o impulsionamento da alimentação fora do lar, a Organização das Nações Unidas para Alimentação e Agricultura (FAO) realizou a primeira definição formal para "comida de rua” em 1986, que inclui o amplo arranjo de comércio de venda de alimentos e bebidas preparados na maioria das vezes em ambientes públicos, notavelmente nas ruas, para o consumo imediato ou posterior, sem apresentarem, contudo, etapas adicionais de preparo ou processamento (WHO, 1996 apud Fellows \& Hilmi, 2011). Cardoso (2009) diz que a

comida de rua também constitui um reflexo da condição econômica e social do país, na medida em que delineia uma alternativa alimentar e nutricional de fácil aquisição, tanto pela acessibilidade física como social, devido ao seu menor custo. (Cardoso, 2009, p. 1216)

A partir desse breve exposto, detemo-nos em uma manifestação específica, oriunda da dinâmica urbana: a "comida de rua" comercializada nos food trucks. De forma ampla, é preciso entender como se estabeleceu esse modelo de negócio nas sociedades urbanas. A versão mais recorrente é de que os food trucks surgiram nos Estados Unidos nos anos de 1870 para atender operários da construção civil. Em Los Angeles, por exemplo, entre 1880 e 1890, uma espécie de "carrinhos de mão com paredes" revelavam os cozinheiros vendendo tamales [1] para trabalhadores e consumidores dos bares locais do subúrbio. No começo do século XX, argelinos ingressaram de forma maciça no negócio (Vallianatos, 2017, p. 69) dado que os estúdios de filmes, refinarias de petróleo, corporações nacionais e empresas aéreas ajudavam a fazer da região um centro múltiplo, rodeado por subúrbios residenciais.

Com a Segunda Guerra Mundial, centenas de milhares de trabalhadores adicionais se mudaram para o sul da Califórnia e precisavam de lugares para comer, ou seja, havia uma demanda local por cafeterias para a parte da manhã e de locais para almoço. Ao chegar a essas regiões, os food trucks trouxeram comida para dentro dos distritos industriais. Já nos anos de 1970, a Califórnia foi o primeiro estado a ter o serviço de refeições quentes oferecidas em grandes carros equipados com cozinhas. Essa revolução foi iniciada por alguns empreendedores independentes voltados para o que se denomina em inglês como catering e pode ser entendido como entrega ou oferta de comida pronta em português. Ao final da década, esse grupo tornou-se pioneiro na Associação de Catering Industrial (Vallianatos, 2017, p. 71).

Com a chegada do século XXI, o número de food trucks dobrou graças à recessão econômica que fez com que entre 2007 e 2012, 1.400 novos food trucks estivessem em atividade em cidades ao redor dos Estados Unidos. Nessa época, a Associação Nacional de Restaurantes dos Estados Unidos estimou que a indústria da comida móvel vendia cerca de 650 milhões de dólares, o que representava um por cento das receitas do setor. No mesmo período, muitas cidades estadunidenses começaram a debater como tornar a atividade dos food trucks habilitada. Em 2015, a cidade de Nova York contava com 20 mil trabalhadores em suas ruas, muitos deles donos de restaurantes que não conseguiam mais sustentar os aluguéis e salários dos trabalhadores (Ehrenfeuch \& Croegaert, 2017, p.109).

No Brasil, o Serviço Brasileiro de Apoio às Micro e Pequenas Empresa (SEBRAE) indica que em 2014 esse tipo de negócio, inserido no mercado da alimentação fora de casa, movimentou $\mathrm{R} \$ 140$ bilhões no país - um crescimento de cerca de $20 \%$ em relação a 2013 , quando o segmento faturou $\mathrm{R} \$ 116,55$ bilhões. Para a entidade, as cifras podem ser atribuídas a dois fatores: oportunidade de abrir um primeiro restaurante e expandir um já existente, com relativo baixo investimento inicial e promessa de bons retornos (SEBRAE, 2020). 
As capitais São Paulo e Rio de Janeiro ocupam papel central no início desse movimento. Sobre o processo de comida de rua, tal como proposto nessa pesquisa, em São Paulo, a lei no 15.947 (2013), estabeleceu a venda de alimentos na rua por qualquer pessoa, reconhecendo três tipos de comércio: veículos motorizados; tabuleiros e veículos não motorizados (carrinhos de tração humana).

$\mathrm{Na}$ capital fluminense, a presença dos trucks - carros ou trailers, motorizados, novos ou seminovos, que facilitam enormemente o deslocamento - se deu antes mesmo de haver uma legislação específica para estarem nas ruas.

\subsection{A inserção do bem "Rio de Janeiro: Paisagens Cariocas entre a Montanha e o Mar" na Lista de Patrimônios da Humanidade}

Em 2001, a cidade do Rio de Janeiro tentou ingressar pela primeira vez na Lista do Patrimônio Mundial da UNESCO. Investida essa coordenada pelo Ministério do Meio Ambiente e que trazia a proposta de reconhecer o sítio misto, natural e cultural formado por três grandes fragmentos: Parque Nacional da Tijuca (ênfase), Jardim Botânico e Pão de Açúcar. A análise do documento de candidatura foi feita pelo International Council on Monuments and Sites (ICOMOS) e a World Conservation Union (IUCN), consultorias que apoiaram a UNESCO na avaliação da concessão da chancela.

No relatório do ICOMOS, a entidade reconhecia a presença de valores universais na paisagem, como a associação de milhões de moradores à beleza da paisagem e a influência dessa relação em atividades de lazer. Também destacava como esse cenário servia de inspiração nas artes. $\mathrm{O}$ parecer suscitava ainda $\mathrm{o}$ papel do conjunto da Baía, do Pão de Açúcar e da estátua do Cristo Redentor como fatores identitários de reconhecimento mundial. Por outro lado, a avaliação do dossiê apontou para a necessidade de outras partes da cidade serem incluídas a fim da proposta ser compreendida como uma Paisagem Cultural (Batista, 2017).

Em uma segunda tentativa de reconhecimento, em 2012, o dossiê de candidatura "Rio de Janeiro: Paisagens Cariocas entre a Montanha e o Mar" foi apresentado a UNESCO durante a 36a Sessão do Comitê do Patrimônio Mundial, em São Petersburgo, Rússia. A conformação da candidatura incluiu a coordenação do IPHAN em um modelo de trabalho conjunto com o Ministério do Meio Ambiente, a Associação de Empreendedores Amigos da UNESCO, além dos governos estaduais e municipais do Rio de Janeiro e parceiros privados e públicos.

O reconhecimento da primeira área urbana do mundo considerada como Patrimônio Mundial incluída na categoria Paisagem Cultural ocorreu em junho de 2012. A candidatura do Rio atendeu três dos dez Critérios de Avaliação que compõe a Convenção do Patrimônio Mundial, podendo ser assim resumidos: a) seleção de bens culturais, o que equivale a ser a manifestação de um intercâmbio considerável de valores humanos no desenvolvimento da arquitetura, artes, planejamento urbano ou paisagismo; b) seleção de bens culturais, ou seja, ser exemplo excepcional de um tipo de edifício ou de conjunto arquitetônico ou tecnológico, ou de paisagem que ilustre uma ou várias etapas significativas da história da humanidade; c) seleção de bens culturais, isto é, estar associado a acontecimentos ou tradições vivas, com ideias ou crenças, ou com obras artísticas ou literárias de significado universal excepcional.

A candidatura, da forma que foi feita, trouxe efeitos para uma nova segmentação nas categorias de Patrimônio. Até então, o valor universal atribuído a uma paisagem havia sido conferido somente a áreas rurais, sistemas agrícolas tradicionais, jardins históricos e outros locais de cunho simbólico. Ribeiro (2015) avalia que a incorporação do sítio urbano do Rio de Janeiro na Lista de Patrimônio Mundial na categoria Paisagem Cultural representa um avanço para um entendimento mais amplo de patrimônio mundial, permitindo então que se fale de paisagem cultural urbana.

O avanço a que se refere o autor resulta do fato da categoria Paisagem Cultural ter sido concebida pela UNESCO no ano de 1992 no intuito de mitigar a dicotomia entre natureza e produção humana, aspecto 
que vinha sendo debatido desde a Conferência Geral da Organização das Nações Unidas para a Educação, Ciência e Cultura, em Paris em 1972. Com a criação da categoria Paisagem Cultural, o patrimônio inserido em tal chancela engloba duplo aspecto cultural e natural e, desta forma, o bem "Rio de Janeiro: Paisagens Cariocas entre a Montanha e o Mar", ao ser inserido na Lista de Patrimônios da Humanidade, inaugura a noção de que a integração entre natureza, espaço urbano e elementos simbólicos, como identidade e tradições, configura uma nova concepção de patrimônio: a paisagem cultural.

No caso deste bem, os aspectos naturais evidenciam a complexidade da exuberância da natureza, sendo somados a um conjunto arquitetônico urbano associados ao "estilo de vida carioca" constituído por experiências cotidianas ancoradas na cultura das rodas de samba nas calçadas dos botequins, nas peladas[2] no Aterro do Flamengo[3] e nas pessoas de todas as idades que se exercitam no calçadáo do bairro de Copacabana. Tais atividades, comuns na cidade, fortalecem o imaginário e a identidade local e em tal processo, evidencia-se interações ao ar livre em ambiente incrustado entre a montanha e o mar, que são efetivamente uma forma de ver e pensar a cidade do Rio de Janeiro e, apesar de não representa-la como um todo, tornaram-se constitutivas dos traços que compóem o ideário da mesma e refletem os valores em termos de riqueza única reconhecida pela chancela da UNESCO.

\subsection{A ascensão da comida de rua no contexto da categoria Paisagem Cultural}

O processo em prol da inclusão do bem "Rio de Janeiro: Paisagens Cariocas entre a Montanha e o Mar" enquanto patrimônio chancelado pela UNESCO foi resultado de uma atuação conjunta de diferentes grupos, em sua grande maioria vinculados a distintas áreas do poder público, tais como a do patrimônio, do meio ambiente, do urbanismo, entre outras. A partir desse movimento, o Instituto Rio Patrimônio da Humanidade (IRPH), ratificado pela lei n. 5.547 (2012) como órgão estruturado no Gabinete do Prefeito, foi criado para gerir o sítio reconhecido pela UNESCO como Patrimônio Mundial da Humanidade. Por meio das atribuições da IRPH foram realizados vários estudos objetivando subsidiar o tombamento e/ou registro de elementos tangíveis e intangíveis constituintes da cultura carioca. Por meio desse levantamento, a comida e os espaços de alimentação consagrados pelos cariocas foram percebidos como aspectos centrais no processo de reafirmação de uma identidade cultural. No bojo de tal processo foi instituído o decreto que reconheceu como patrimônio da cultura carioca os Vendedores de Mate e Biscoito de Polvilho nas Praias Cariocas. (Instituto Rio Patrimônio da Humanidade. Relatório de Gestão 2009-2016, 2016, pp. 7-8).

Em outro decreto identificou-se e reconheceu-se como patrimônio cultural um conjunto formado por bares e botequins classificados como tradicionais. A tradição a qual o decreto evoca é constituída pelo enquadramento a alguns critérios segundo o SEBRAE, sendo eles: a) Mais de 50 anos de existência; b) Preservar saberes, técnicas e/ou produtos considerados tradicionais; c) Ter uma marca tradicional; d) Comércio transmitido entre gerações; e) Comércio reconhecido por moradores e frequentadores da região como símbolo do bairro. Desta forma, no ano de 2012, catorze estabelecimentos foram declarados Patrimônio Cultural Carioca. De fato, no contexto fluminense, os bares têm importante significado cultural e fazem parte do ideário da cultura local, apesar de não enunciarem uma só cozinha emblemática, tal como conceitua Maciel (2005); entretanto, o que ganha destaque nesse momento é a discussão sobre a relação entre comida e patrimônio.

Em tal contexto, entrevistas realizadas revelam que o reconhecimento atribuído por decreto foi fortalecido por iniciativas empreendidas em âmbito de grupos sociais constituídos por jornalistas, chefs de cozinha, representantes de associações ligadas a gastronomia, entre outros, que juntos promoveram ações como eventos, prêmios, valorização de produtos e modos de fazer ligados a cultura, sendo essa não necessariamente uma cultura alimentar carioca e sim, uma noção de gastronomia enquanto cultura. O debate foi então estendido para o âmbito político, aspecto que se desdobrou para além dos decretos anteriormente 
mencionados, pois conduziu uma série de discussões que resultaram na construção do Marco Referencial da Gastronomia como Cultura no estado do Rio de Janeiro, instituído pela lei no 7.180 (2015).

$\mathrm{Na}$ esteira de tais acontecimentos, insere-se a atividade da comida de rua advinda dos food trucks. Para orientar a atividade foi formado o Conselho Diretor da Associação de Comida Artesanal sobre Rodas do Rio de Janeiro (ACASO), composto inicialmente por dez proprietários de food trucks que, reunidos, buscavam ter voz representativa para fazer a interface com parceiros eventuais no intuito de construir o processo que os levasse a regulamentação da atividade via município (O Globo, 2017). A busca por parceiros aproximou a ACASO do Sindicato de Bares e Restaurantes do Rio de Janeiro (SindRio), parceria que favoreceu abertura de diálogo com a prefeitura da cidade do Rio de Janeiro, na época gerida pelo prefeito Eduardo Paes que, de acordo com entrevistas realizadas durante o trabalho de campo, estava predisposto a: "ativar a comida de rua, de uma maneira mais regulamentada." (Entrevistado, 2019).

Em ambiente favorável, diretrizes foram então debatidas e na esfera do poder executivo no fim do mês de maio de 2015 já estava pronto o Decreto Rio $\mathrm{n}^{\circ}$ 40.251, assinado em 16 de junho daquele ano. $\mathrm{O}$ decreto em tela dispóe sobre os critérios para comercialização de alimentos em veículos automotores (comida sobre rodas) em áreas públicas, pois até então, vigorava a lei 1.876 de 29 de junho de 1992, que dispunha sobre o comércio ambulante no município do Rio de Janeiro, e previa exigências para algumas categorias de vendedores de comida como, por exemplo, as baianas de acarajé e vendedores de angu, mas nada definia para o comércio de comida em veículos motorizados. Ainda por meio do Decreto, oitenta e sete pontos da cidade do Rio de Janeiro, em vinte e seis bairros foram definidos para parada de food trucks. Pelo texto, buscavase promover a atividade gastronômica em bairros com oferta deficitária de bares e restaurantes e traçar um roteiro de Comida sobre Rodas no município. Para tanto, cabia ao dono do food truck o pagamento de taxas que somam cerca de $\mathrm{R} \$ 700$ à prefeitura.

O Decreto também definiu lugares e pontos onde os food trucks poderiam realizar a comercialização de seus produtos; entretanto, a decisão acerca do ponto que cada food truck ocuparia foi estabelecida através de sorteio que ficou a cargo da Empresa de Turismo do Município do Rio de Janeiro (RIOTUR) realizado em dezoito de agosto de 2015. O sorteio garantiu ainda a possibilidade de alternância de pontos, medida justificada sob o argumento da possibilidade de utilização de distintos pontos, não esgotando ou restringindo a variação da oferta nos pontos autorizados pela prefeitura. Paralelamente, exigiu-se obediência a regras de padronização de dimensões dos veículos sendo essas limitadas a sete metros de comprimento, dois e meio de largura e três de altura e ainda obediência a regras de higiene emanadas pela Vigilância Sanitária.

A elaboração de normativas previa a promoção de algum nível de amparo e regulação deste tipo de comércio, aspecto que somado a definição dos pontos de parada dos food trucks contribuiu para impulsão de negócios recém criados em um momento em que a cidade do Rio de Janeiro vivenciava um ambiente de expectativa de grandes negócios resultantes dos megaeventos supracitados. Em tal contexto, eventos paralelos tornavam a atividade dos food trucks vantajosa pois, em abril de 2016, ocorreu a primeira edição do Festival Parque Passeio Público por iniciativa do Movimento Rio ao Ar Livre[4], que propunha ações multiculturais a fim de promover a ocupação regular do Parque Passeio Público, espaço construído em 1783 e que logo se tornou ponto de encontro no centro da cidade do Rio de Janeiro em razão de ser o primeiro espaço ajardinado do Brasil. Ao longo do ano, outras edições do Festival foram realizadas evidenciando a valorização de atividades ao ar livre, com programação de lazer para adultos e recreação para crianças. Em quase todas as edições, a oferta de comida era feita por barraquinhas e também por food trucks.

A proposta do evento foi anunciada no portal Visit.Rio, criado pela RIOTUR e o Rio Convention \& Visitors Bureau. Para além de publicar sobre os eventos com food trucks, o portal passou a oferecer uma sessão para eles, descrita como "A gastronomia carioca num ambiente descontraído. Quando a fome bater nos intervalos entre uma atração e outra. Trucks oferecem o melhor da gastronomia de rua para alimentar os olhos, o paladar e a alma!" (Visit.Rio, 2016). 
A plataforma virtual Visit.Rio foi lançada em dezembro 2015, cerca de seis meses antes dos Jogos Olímpicos Rio 2016, com o intuito de unificar a comunicação dos atrativos turísticos e substituir o Guia Rio, publicação mensal oficial editada pela RIOTUR durante quarenta anos. O lançamento da plataforma objetivava não somente promover o turismo carioca, mas também facilitar as interações de lazer e evidenciar o que havia de mais novo e interessante na cidade, aspectos que podem ser confirmados pelas palavras do então presidente do Rio Convention \& Visitors Bureau, Alfredo Lopes:

Nos dias de hoje, a internet é uma das ferramentas mais utilizadas para atingir os principais mercados. Com o Visit.Rio, o Rio não apenas se posiciona como um produto turístico preparado para receber e dar todo o suporte necessário aos nossos visitantes, mas, também, como um destino precursor no Brasil na forma de divulgar seus atrativos e serviços (Lopes, A., 2015, $[$ n.p]).

Assim, pode-se dizer que os food trucks entraram numa agenda ampla, sustentada por associações de cunho privado e por instituições do poder público, em contexto peculiar conforme destacou um integrante da ACASO em entrevista:

O Rio é uma metrópole muito plural, temos migrantes do país inteiro, o que traz uma diversidade cultural muito grande e a gastronomia tá incluída nisso. E por ser uma cidade de muita beleza, as pessoas querem estar na rua. Existe uma cultura de comida de rua no Rio, mas que não está totalmente associada à comida de qualidade. Temos alguns pioneiros que conseguem entregar as duas coisas, mas é mais um caldo, um acarajé, mas que são exceções. A comida de rua ainda é vista como barata. E os food trucks chegaram com uma proposta diferente (Entrevistado, 2019).

\section{Discuss Ão: ARTiCulando FOOD TRUCKs, PATRIMÔNiO E TURismo}

O uso de métodos de pesquisa distintos orientados pelo referencial antropológico e pautados na observação do processo a partir do conceito de turismização permitiu entrelaçar questões que são comuns aos campos da alimentação, turismo e patrimônio percorrendo de forma transdisciplinar aspectos que evidenciam a compreensão dos food trucks enquanto fenômeno classificado como cozinha sobre rodas, ou seja, uma construção cultural apoiada em uma identidade que se manifesta reunida ao lazer ao ar livre. Tal construção não seria possível apartada de um contexto de reversão de uma identidade associada a imagem de uma cidade deteriorada pela violência, o que até aquele momento caracterizava o Rio de Janeiro. De forma identitária, lugares diferenciam de outros por promoverem conexões múltiplas tais como ideias, pessoas, setores produtivos e governos que, apoiados em seus patrimônios culturais de ordem material e imaterial, assim como as paisagens culturais, definem em relação ao outro o que nos representa e identifica.

As cozinhas sobre rodas tornaram-se um capital simbólico acionado no processo descrito ao longo do artigo justamente por se autoconstruírem em uma lógica expressa na fala do entrevistado mencionado no final da seção anterior: "E os food trucks chegaram com uma proposta diferente" (2019). O diferente ao qual o entrevistado se refere é a própria construção da noção de gastronomia no contexto contemporâneo. Recuando a década de 1980, concomitantemente às mudanças nas formas de alimentação descritas no item 4.1 do presente trabalho, o Brasil recebeu grandes chefs franceses para assumir o trabalho das cozinhas de hotéis de luxo. Nomes como Paul Bocuse, Claude Troisgros e Emmauel Bassoleil passaram a trabalhar no país, conferindo a tais espaços e pratos elaborados significados distintos dos até então atribuídos a comida, a começar pela questão de gênero, pois as cozinhas associadas ao luxo são ocupadas por chefs do gênero masculino. Somente na década de 1990, os ambientes das cozinhas profissionais, começaram ser liderados por profissionais mulheres, como Ana Luiza Trajano, Carla Pernambuco e Roberta Sudbrack (Freixa \& Dolores, 2017).

A partir dos anos 2000, as bancadas das cozinhas foram abertas e levadas para megaeventos gastronômicos com a presença de públicos significativos. Programas de TV foram repaginados em múltiplas abordagens envolvendo desde preparos de receitas até competições gastronômicas e programas onde viagens exploravam a cozinha como um cenário de relações entre pessoas e de identificação de uma determinada região. Para Jacob 
(2013) as transformações da cozinha ao longo do século XX foram registradas pela comunicação tais como jornais, revistas, literatura, rádio e, especialmente, a televisão; pelo viés da mudança do espaço dedicado ao que era antes classificado como "culinária” para o espaço dedicado à "gastronomia”. Da análise produzida pela autora supracitada, aqui definimos e consideramos a gastronomia enquanto construção social pautada em distintos valores, tais como a ressignificação do status social atribuído ao profissional gerenciador da cozinha, ou seja, o chef de cozinha, a midiatização do que era antes a culinária, ressignificação de valores sobre função e prazer no ato da alimentação.

As cozinhas sobre rodas buscaram se diferenciar, reivindicando uma associação ao que o entrevistado denominou como "comida de qualidade" distinguindo a categoria de outra, a qual reúne os vendedores de "comidas sem qualidade". Cabe destacar que as cozinhas sobre rodas não implicaram em uma substituição e/ ou exclusão das tradicionais carrocinhas de venda de cachorro-quente, angu, acarajé, milho, churrasquinho, entre outros tipos de alimentos. Ambas as plataformas de oferta de comida de rua coexistiram desde o início, com dinâmicas e características próprias de funcionamento. A das cozinhas sobre rodas assentou-se na distinção que passa por oferecer uma "comida artesanal" e não por acaso, a Associação que reúne o projeto das cozinhas sobre rodas é denominada Associação de Comida Artesanal sobre Rodas do Rio de Janeiro. Neste sentido, a gastronomia, conforme conceito exposto anteriormente no caso das cozinhas sobre rodas, incide sobre a oferta de "comida de qualidade", identificada como artesanal e sobre a forma de seu consumo que ocorre ao ar livre.

Tais sentidos, quando investigados em articulação com processos de patrimonialização construídos em parceria com políticas de turismo, facultam a percepção de desdobramentos não somente no campo econômico, mas também cultural. No caso das cozinhas sobre rodas, o processo que reconheceu a paisagem cultural como patrimônio da humanidade, ao ser analisado pelo âmbito da atividade turística, revela a tentativa de reversão da hegemonia do turismo de sol e praia em franco acirramento da competitividade entre destinos turísticos que buscam atender um perfil de turistas interessado em maior interação com a realidade visitada (Valls, 2004). O reconhecimento da paisagem carioca enquanto patrimônio da humanidade fortalece assim possibilidades inseridas no denominado turismo cultural e amplia a própria noção de atrativos culturais, expandido o rol para além dos percebidos como tradicionais (como museus e monumentos históricos), ao incluir modos de se relacionar com a cidade às práticas gastronômicas.

No âmbito da atividade turística decorrente do fluxo de visitantes que compreende o período de concentração de distintos eventos na cidade do Rio de Janeiro, as cozinhas sobre rodas foram inseridas no contexto em análise enquanto serviço capaz de incrementar pontos diversos da cidade, funcionando ainda como parte diferenciada na engrenagem de oferta de alimentos, quer pela associação à "comida de qualidade" ou pela condição de rápida e fácil circulação. A partir da discussão aqui empregada, entendese que as cozinhas sobre rodas se encaixaram no processo de turismização que esteve em curso durante o período dos megaeventos e do boom de patrimonializações concentradas entre os anos 2012 a 2017 numa função maior de promover a sociabilidade adequada aos objetivos de ressignificação e de embelezamento da cidade almejado, em partes, por meio da reafirmação de uma identidade simbolizada no bem "Rio de Janeiro: Paisagens Cariocas entre a Montanha e o Mar" e fortalecidas por intermédio do Poder Público. Tal como Jafari (2005) destaca ao mencionar as estruturas de poder presentes na orientação do processo de indução da atividade turística.

\section{Conclusão}

Ao longo do artigo, demonstrou-se que as cozinhas sobre rodas podem ser interpretadas através do cruzamento de contextos globais e locais. Nesta perspectiva, inserem-se em um processo de construção de imagens, ou seja, construção de um processo pelo qual se deseja ser visto ou reconhecido. Entretanto, tomando como referência o significado cultural do processo analisado, uma das considerações que se 
permite fazer é de que a proposta de comida de rua e a oferta feita por cozinhas sobre rodas reforçaram uma sociabilidade que parece ter sido a que mais se encaixou nas transformações demandadas para o fortalecimento da identidade que o poder público buscava apresentar. Paralelamente, as cozinhas sobre rodas também foram acionadas enquanto elementos associados a modernização, inovação, criatividade, organização e limpeza urbana e social; sendo esse conjunto de elementos entrelaçados a comida de qualidade por ser produzida de forma artesanal.

A cozinha sobre rodas se mostrou útil na geração de aspectos tangíveis e intangíveis, como por exemplo a "redescoberta" do comer ao ar livre como uma atividade vinculada ao lazer e consequentemente apropriada ao turismo, pois foi justamente a itinerância e a sociabilidade nas ruas da cidade que permitiu acessar a chancela de Patrimônio da Humanidade dentro da categoria Paisagem Cultural, que privilegiou entre outros aspectos que particularizam a paisagem carioca, as vivências nos espaços abertos, ao ar livre e os encontros nas ruas.

\section{REFERÊNCIAS}

Abreu, R. (2015) Patrimonialização das diferenças e os novos sujeitos de direito coletivo no Brasil. Em C. Tardy \& V. Dodebei (Orgs.) Memória e Novos Patrimônios. (pp. 67-93). Open Edition, Saint Hilaire.

Aguiar, L. B. (2016). O Programa de Cidades Históricas, o turismo e a "viabilidade econômica" do patrimônio (1973-1979). Em Anais do Museu Paulista. Estudo de Cultura Material, 24(1), pp. 137-149. https://doi.org/1 0.1590/1982-02672016v24n0105

Almeida, L. F. (2007, julho, 11). O futuro é a paisagem. O Globo. Recuperado em 5 outubro, 2016 de http://www.c ultura.gov.br/noticias.

Barreto, M. (2003). O imprescindível aporte das ciências sociais para o planejamento e a compreensão do turismo. Revista Horizontes Antropológicos, 9(20), pp. 15-29. https://doi.org/10.1590/S0104-71832003000200002.

Batista, M. A. N. (2009). Candidatura do Rio de Janeiro a patrimônio mundial: Categoria paisagem cultural. $8^{\circ}$ Seminário Docomomo Brasil. Sumário de Trabalho (pp. 1-4). Rio de Janeiro, RJ, Brasil. Recuperado em 04 setembro, 2020 de http://www.docomomo.org.br.

Cardoso, R. C. V., Santos, S. M. C., \& Silva, E. O. (2009). Comida de rua e intervenção: estratégias e propostas para o mundo em desenvolvimento. Ciência \& Saúde Coletiva, 14(4), 1215-1224. https://doi.org/10.1590/S141381232009000400027.

Choay, F. (2006). Alegoria do Patrimônio. São Paulo: Estação Liberdade: UNESP.

Chuva, M. (2017). Os arquitetos da memória. Rio de Janeiro: Editora UFRJ.

Correa, R. M. (2015). Turismo cultural no Brasil: uma abordagem histórica à luz de Michel Parent (1966-1967). Anais do XXVIII Simpósio Nacional de História. Universidade Federal de Santa Catarina, Florianópolis.

Cunha, O. M. G. (2004). Tempo imperfeito: uma etnografia do arquivo. Mana, 10(2), pp. 287-322. https://doi.org /10.1590/S0104-93132004000200003.

Decreto-Lei n. 25, de 30 de novembro de 1937. Organiza a proteção do patrimônio histórico e artístico nacional. Recuperado de http://www.planalto.gov.br/ccivil_03/Decreto-Lei/Del0025.htm.

Decreto n. 35.879 de 05 de julho de 2012. Dispóe sobre o Rio como patrimônio da humanidade e dá outras providências. Recuperado de http://smaonline.rio.rj.gov.br/legis_consulta/42562Dec\%2035879_2012.pdf.

Decreto n. 40.251 de 15 de junho de 2016. Dispõe sobre os critérios para comercialização de alimentos em veículos automotores (comida sobre rodas) em áreas públicas e dá outras providências. Recuperado em https://leismunicipais.com.br/a1/rj/r/rio-de-janeiro/decreto/2015/4025/40251/decreto-n-40251-2015dispoe-sobre-os-criterios-para-comercializacao-de-alimentos-em-veiculos-automotores-comida-sobre-rodas-em -areas-publicas-e-da-outras-providencias.

Ehrenfeuch, W., \& Croegaert, A. (2017). Learning from New Orleans: Will revising or relaxing public space ordinances create a just environment for street commerce? In Agyeman, J., Matthews, C., \& Sobel, H (Ed.), Food 
Trucks, Cultural Identity, and Social Justice: From Loncheras to Lobsta Love. (Cap. 6, pp. 109-125). Cambridge, Massachusetts: The MIT Press.

Fellows, P., \& Hilmi, M. (2011). Selling street and snack foods. Rural Infrastructure and Agro-Industries Division Food and Agriculture Organization of the United Nations: Rome. Recuperado de http://www.fao.org/3/i2474e/i2 474e00.pdf.

Fernandes, J. R. O. (2010). Muito antes do SPHAN: a política de patrimônio histórico no Brasil (1838-1937). Anais do Encontro Politicas Culturais: teorias e práxis. Rio de Janeiro: Fundação Casa de Rui Barbosa.

Freixa, D. \& Chaves, G. (2009). Gastronomia no Brasil e no mundo. Rio de Janeiro: Senac.

Giumbelli, E. (2002). Para Além do "Trabalho de Campo": Reflexões supostamente malinowskianas. Revista Brasileira de Ciências Sociais. 17(48), pp. 91-107. https://doi.org/10.1590/S0102-69092002000100007.

Goldenberg, M. (2007). A arte de pesquisar: como fazer pesquisa qualitativa em ciências sociais (10a ed.) Rio de Janeiro: Record.

Guimarães, C. (2015, janeiro, 15) Associação carioca de 'foodtruqueiros' ganha nome oficial. O Globo. Recuperado em 12 outubro, $2017 \mathrm{em}$ http://blogs.oglobo.globo.com/gente-boa/post/associacao-carioca-de-foodtruqueiros -ganha-nome-oficial-558690.html.

IPHAN. (2011). Dossiê Patrimônio Mundial: Paisagens Cariocas entre a Montanha e o Mar. Comitê Técnico da Candidatura do Rio a Patrimônio Mundial, Rio de Janeiro: IPHAN. Recuperado em 14 abril, 2018 de http://portal.iphan.gov.br/uploads/ckfinder/arquivos/Dossi\%C3\%AA\%20portugu\%C3\%AAs\%2028\%20 mar\%C3\%A7o\%202011\%20RJ.pdf.

Jacob, M. H. A. (2013). Gastronomia, culinária e mídia: estudos dos ambientes midiáticos e das linguagens da comida e da cozinha. (Tese de doutorado). Pontifícia Universidade Católica de São Paulo, São Paulo, Brasil. Recuperado de https://tede2.pucsp.br/handle/handle/4497?mode=full.

Jafari, J. (1994) La cientifización del turismo. Revista Estudios y Perspectivas em Turismo, 3(1), pp.7-35.

Lei n. 1.876, de 29 de junho de 1992. Dispõe sobre o comércio ambulante no município e dá outras providências. Recuperado de https://leismunicipais.com.br/a/rj/r/rio-de-janeiro/lei-ordinaria/1992/187/1876/lei-ordinari a-n-1876-1992-dispoe-sobre-o-comercio-ambulante-no-municipio-e-da-outras-providencias.

Lei n. 5.547, de 27 de dezembro de 2012. Dispõe sobre a Reestruturação da Organização Básica do Poder Executivo do Município do Rio de Janeiro e dá outras providências. Recuperado de http://www.rio.rj.gov.br/dlstatic/10112 /4455734/4112402/43559Lei5547_2012.pdf.

Lei n. 15.947, de 26 de dezembro de 2013. Dispõe sobre as regras para comercialização de alimentos em vias e áreas públicas - comida de rua - e dá outras providências. Recuperado de https://leismunicipais.com.br/a/sp/s/sao-paulo/lei-ordinaria/2013/1594/15947/lei-ordinaria-n-15947-20 13-dispoe-sobre-as-regras-para-comercializacao-de-alimentos-em-vias-e-areas-publicas-comida-de-rua-e-da-out ras-providencias.

Lei n. 7.180, de 28 de dezembro de 2015. Estabelece, no âmbito do estado do Rio de Janeiro, o marco referencial da gastronomia como cultura e dá outras providências. Recuperado de http://alerjln 1.alerj.rj.gov.br/CONTLEI.N SF/e9589b9aabd9cac8032564fe0065abb4/06033f24c3697dab83257f31005b1d36?OpenDocument.

Maciel, M. E. (2005). Olhares antropológicos sobre a alimentação: identidade cultural e alimentação. In Canesqui, A. M. \& Garcia, R. W. D. (Orgs.). Antropologia e nutrição: um diálogo possivel [online]. Rio de Janeiro: Editora FIOCRUZ, 2005. Recuperado em http://books.scielo.org/id/v6rkd/pdf/canesqui-9788575413876-03.pdf.

Mendonça, T. C. M. (2010) Queparaiso éesse? A turismização da Ilha Grande Tese de Doutorado, Instituto de Filosofia e Ciências Humanas, Universidade do Estado do Rio de Janeiro, RJ, Brasil.

Movimento Rio Ao Ar Livre. (2015, agosto, 21). Recuperado em 12 outubro, 2017 em www.facebook.com/ movimentorioaoarlivre.

O Globo. (2015, dezembro, 22). Nova marca, Visit.Rio, é lançada para promover turismo carioca. Recuperado em 23 junho, 2019 de https://oglobo.globo.com/rio/nova-marca-visitrio-lancada-para-promover-turismo-carioca-18 348826.

Oliveira, M. M. (2007). Como fazer pesquisa qualitativa. Petrópolis: Vozes. 
Parent, M., \& Leal, C. F, B. (2009). As Missóes da UNESCO no Brasil: Michel Parent. Rio de Janeiro: IPHAN COPEDOC.

Poulot, D. (2011). Cultura, História, valores, patrimoniais e museus. Varia História, 27(46), pp. 471-480. https://d oi.org/10.1590/S0104-87752011000200004.

Prefeitura do Rio de Janeiro. Instituto Rio Patrimônio da Humanidade. (2016). Relatório de Gestão 2009-2016. Recuperado em 23 junho, 2019 de http://portal.iphan.gov.br/uploads/ckfinder/arquivos/Relatorio_de_Gesta o_2016.pdf

Ribeiro, R. W. (2015). Paisagem Cultural Urbana e Paisagem Histórica Urbana: o Rio de Janeiro e os desafios para a Lista do Patrimônio Mundial. Identidades. Território, Projeto, Patrimônio, 6(19), pp. 235-256. http://dx.do i.org/10.5821/identidades.8837.

Rios, D. A., \& Oliveira, M. A. S. A. (2018). O Lugar do Turismo nas Políticas Culturais: o caso do Boulevard Olímpico. Revista Mouseion, (31), pp. 59-74. http://dx.doi.org/10.18316/mouseion.v0i31.5289.

SEBRAE. (2017). O mercado de food trucks. Recuperado em 24 setembro, 2017 de http://www.sebrae.com.br/sites/P ortalSebrae/ufs/mg/artigos/o-mercado-de-food-trucks,2e491bc9c86f8510VgnVCM1000004c00210aRCRD.

SEBRAE. (2020) Food trucks: como atuar neste modelo de negócio. Recuperado em 01 setembro, $2020 \mathrm{em}$ https://m.sebrae.com.br/sites/PortalSebrae/artigos/food-truck-uma-nova tendencia,d128e6f7c633c410VgnVCM2000003c74010aRCRD.

Tribe, J. (1997). The (in) discipline of tourism. Annals of Tourism Research, 24(3), pp. 638-657.

Vallianatos, M. (2017). To Serve and Protect: Food trucks and Food Safety in a Transforming Los Angeles. In Agyeman, J., Matthews, C., \& Sobel, H (Ed.), Food Trucks, Cultural Identity, and Social Justice: From Loncheras to Lobsta Love. (Cap. 4, pp. 67-83). Cambridge, Massachusetts: The MIT Press.

Valls, J. F. (2006). Gestão integral de destinos turísticos sustentáveis. Tradução de Cristiano Vasques e Liana Wang.Rio de Janeiro: Editora FGV.

\section{Notas}

[1] Iguaria muito comum no México, semelhante a pamonha, que pode ser cozida a vapor ou então fervida

[2] Expressão verbal comum na cidade do Rio de Janeiro para designar jogo de futebol entre amigos e com regras estabelecidas pelo próprio grupo participante da atividade.

[3] Extensa área de lazer localizada a beira da praia do bairro do Flamengo situado na Zona Sul da cidade do Rio de Janeiro.

[4] De acordo com a página do Movimento Rio Ao AR Livre na rede social Facebook, a ideia da construção do grupo originou-se do desejo de promover uma "reocupação urbana". O projeto, criado em 2015 foi apresentado a Prefeitura da cidade do Rio de Janeiro e desde então, em parceria com a Prefeitura foram organizadas ações ao livre como eventos de várias naturezas em espaços públicos antes esvaziados em decorrência da degradação social e violência urbana. Recuperado de www.facebook.com/movimentorioaoarlivre. 